\title{
Polymorphism of Nitric Oxide Synthase 1 Affects the Clinical Phenotypes of Ischemic Stroke in Korean Population
}

\author{
Seung Don Yoo, MD, $\mathrm{PhD}^{1}$, Jun Sang Park, $\mathrm{MD}^{1}$, Dong Hwan Yun, $\mathrm{MD}, \mathrm{PhD}^{1}$, Hee-Sang Kim, MD, $\mathrm{PhD}^{1}$, \\ Su Kang Kim, $\mathrm{PhD}^{2}$, Dong Hwan Kim, MD, $\mathrm{PhD}^{1}$, Jinmann Chon, $\mathrm{MD}$, $\mathrm{PhD}^{1}$, Goun Je, $\mathrm{MD}^{1,3}$, \\ Yoon-Seong Kim, MD, PhD ${ }^{3}$, Joo-Ho Chung, MD, $\mathrm{PhD}^{2}$, Seung Joon Chung, $\mathrm{MD}^{1}$, Jin $\mathrm{Ah}$ Yeo, $\mathrm{MD}^{1}$ \\ ${ }^{1}$ Department of Physical Medicine and Rehabilitaion, Kyung Hee University Medical Center, Seoul, Korea; \\ ${ }^{2}$ Kohwang Medical Research Institute, Kyung Hee University School of Medicine, Seoul, Korea; \\ ${ }^{3}$ Burnett School of Biomedical Sciences, University of Central Florida College of Medicine, Orlando, FL, USA
}

Objective To investigate whether four single nucleotide polymorphisms (SNPs) rs2293054 [Ile734Ile], rs1047735 [His902His], rs2293044 [Val1353Val], rs2682826 (3'UTR) of nitric oxide synthase 1 (NOS1) are associated with the development and clinical phenotypes of ischemic stroke.

Methods We enrolled 120 ischemic stroke patients and 314 control subjects. Ischemic stroke patients were divided into subgroups according to the scores of the National Institutes of Health Stroke Survey (NIHSS, $<6$ and $\geq 6$ ) and Modified Barthel Index (MBI, $<60$ and $\geq 60$ ). SNPStats, SNPAnalyzer, and HelixTree programs were used to calculate odds ratios (ORs), 95\% confidence intervals (CIs), and p-values. Multiple logistic regression models were performed to analyze genetic data.

Results No SNPs of the NOS1 gene were found to be associated with ischemic stroke. However, in an analysis of clinical phenotypes, we found that rs2293054 was associated with the NIHSS scores of ischemic stroke patients in codominant $(\mathrm{p}=0.019)$, dominant $(\mathrm{p}=0.007)$, overdominant $(\mathrm{p}=0.033)$, and log-additive $(\mathrm{p}=0.0048)$ models. Also, rs2682826 revealed a significant association in the recessive model $(\mathrm{p}=0.034)$. In allele frequency analysis, we also found that the $\mathrm{T}$ alleles of rs2293054 were associated with lower NIHSS scores ( $\mathrm{p}=0.007)$. Respectively, rs2293054 had a significant association in the MBI scores of ischemic stroke in codominant $(\mathrm{p}=0.038)$, dominant $(\mathrm{p}=0.031)$, overdominant ( $\mathrm{p}=0.045)$, and log-additive $(\mathrm{p}=0.04)$ models.

Conclusion These results suggest that NOS1 may be related to the clinical phenotypes of ischemic stroke in Korean population.

Keywords Nitric oxide synthase 1, Polymorphism, Ischemic stroke, National Institutes of Health Stroke Survey, Modified Barthel Index

Received June 2, 2015; Accepted July 22, 2015

Corresponding author: Jun Sang Park

Department of Physical Medicine and Rehabilitation, Kyung Hee University Medical Center, 23 Kyungheedae-ro, Dongdaemun-gu, Seoul 02447, Korea Tel: +82-2-958-8565, Fax: +82-2-958-8560, E-mail: leadernadakkk@hanmail.net

(c) This is an open-access article distributed under the terms of the Creative Commons Attribution Non-Commercial License (http://creativecommons.org/ licenses/by-nc/4.0) which permits unrestricted noncommercial use, distribution, and reproduction in any medium, provided the original work is properly cited. Copyright $\odot 2016$ by Korean Academy of Rehabilitation Medicine 


\section{INTRODUCTION}

Stroke is a serious neurological disease which is the leading cause of severe disability and the second most common cause of death $[1,2]$. Stroke can be subdivided into ischemic stroke (IS) and hemorrhagic stroke. IS accounts for approximately $80 \%$ of all strokes and results from vascular occlusion [3]. The IS may be a highly multifactorial disease consisting of a group of heterogeneous disorders with multiple genetic and environmental risk factors [4]. Several lines of evidence have consistently suggested a genetic influence on the risk and prognosis of IS [5]. Although genetic polymorphisms of several candidate genes for IS have been studied by case control analysis, few associations have been consistently replicated [5].

The role of nitric oxide (NO) was investigated in in vivo models of cerebral ischemia [6]. NO is produced using $\mathrm{L}$-arginine as the substrate and nitric oxide synthase (NOS) is responsible for synthesis. In human beings, three isoforms of NOS, which are NOS1, NOS2, NOS3 are identified. NOS1 is the so-called neuronal NOS and is mainly expressed in the brain. It is reported to play a role in central nervous system synaptic plasticity, reduced sympathetic activity and reduced tone in various smooth muscles. NOS2 is known as inducible NOS and is mainly induced in macrophages, which represent a cytotoxic principle. NOS3 is so-called endothelial NOS and is expressed in endothelial cells. It reportedly dilates all types of blood vessels [7]. In the early phase after ischemia, NO is produced by the constitutive endothelial and neuronal isoforms of nitric oxide synthase (NOS3 and NOS1) [6]. Although NOS3 appears beneficial via vasodilatation and inhibition of leukocyte adhesion and platelet aggregation, NOS1 was demonstrated to be deleterious in cerebral ischemia. Moreover it is now thought that NO induced neuronal death is mainly mediated through the formation of very reactive peroxynitrite, resulting from the reaction between NO and superoxide anion [6]. In terms of variation in NO availability, a risk for IS could be explained in part by NOS1 genetic polymorphism [8-10]. Although previous studies reported a relationship between NOS1 genetic polymorphism and the susceptibility of IS, important clinical phenotypes were not included in their analysis [8-10]. Therefore, we evaluated not only the genetic association between NOS 1 polymorphisms and the susceptibility of IS, but also clinical phenotypes of IS patients in a Korean population.

\section{MATERIALS AND METHODS}

\section{Subjects and clinical phenotypes}

IS patients were recruited at the Stroke Center of Kyung Hee University Hospital and Emergency Department in Kyung Hee University Medical Center from October 2007 to December 2009. One hundred twenty-one IS patients (67 males, 53 females; $65.8 \pm 12.2$ years) 1 week to 1 month from onset were enrolled (Table 1). Subjects with transient ischemic attack, traumatic brain injury, brain tumors, congenital brain disorders, cardiovascular malformation, chronic inflammatory diseases, auto-immune diseases and neuropsychiatric disorders were excluded. Each stroke patient was diagnosed through neurological examinations, computed tomography (CT), magnetic resonance imaging (MRI), angiography, and duplex sonography. All stroke patients were classified into two clinical phenotypes using the National Institutes of Health Stroke Survey (NIHSS) score and the Modified Barthel Index (MBI) score. For the prognosis of stroke patients, the severity of 13 neurological symptoms were assessed using the NIHSS score. For hospitalization, the quality

Table 1. Patients' characteristics

\begin{tabular}{lcc}
\hline & IS group & Control group \\
\hline Sex (male:female) & $67: 53$ & $176: 138$ \\
Age (yr) & $65.8 \pm 12.2$ & $63.1 \pm 9.4$ \\
NIHSS score & & \\
$\quad<6$ & 56 & - \\
$\quad \geq 6$ & 56 & - \\
MBI score & & \\
$\quad<60$ & 70 & - \\
$\quad \geq 60$ & 25 & - \\
Hypertension & & \\
$\quad(-)$ & 35 & - \\
$(+)$ & 80 & - \\
Diabetes mellitus & & - \\
$\quad(-)$ & 71 & - \\
\hline$(+)$ & 45 & \\
\hline
\end{tabular}

Values are presented as number or mean \pm standard deviation.

IS, ischemic stroke; NIHSS, National Institute of Health Stroke Scale; MBI, Modified Barthel Index. 
of 10 activities of general life was estimated by the MBI score. Age-matched control subjects $(\mathrm{n}=314 ; 176$ males, 138 females; $63.1 \pm 9.4$ years) were selected through a general health check-up program (Table 1). Participants with symptoms or history of neurological diseases, ischemic heart diseases, or any severe diseases were excluded. This study was approved by the ethics review committee of Medical Research Institute, Kyung Hee University College of Medicine, and written informed consent were obtained from both the IS patients and control subjects.

\section{SNP selection and genotyping}

We selected four, single nucleotide polymorphisms (SNPs) with greater than 0.1 heterozygosity among SNPs located in the coding regions or 3'-untranslated region (UTR) of the NOS1 gene which were searched at the dbSNP database (http://www.ncbi.nlm.nih.gov/SNP; dbSNP Build 131) [11,12]. SNPs with unknown heterozygosity, minor allele frequency below $4 \%$ were excluded. Finally, four SNPs were selected and analyzed: rs2293054 [Ile734Ile], coding-synonymous; rs1047735 [His902His], coding-synonymous; rs2293044 [Val1353Val], codingsynonymous; rs2682826, 3'-UTR. Peripheral blood samples were collected from all participants and then preserved in a $-70^{\circ} \mathrm{C}$ refrigerator for further laboratory procedures. The polymerase chain reaction (PCR) comprised 35 cycles at $94^{\circ} \mathrm{C}$ for 30 seconds, $58^{\circ} \mathrm{C}$ for 30 seconds, $72^{\circ} \mathrm{C}$ for 1 minute, and 1 cycle at $72^{\circ} \mathrm{C}$ for $5 \mathrm{~min}$ utes for the final reaction. PCR products were sequenced using an ABI PRISM 3730XL analyzer (PE Applied Biosystems, Foster City, CA, USA). Sequence data were analyzed using the SeqMan II software (DNASTAR Inc., Madison, WI, USA).

\section{Statistical analysis}

Hardy-Weinberg equilibrium (HWE) was assessed using a chi-squared test. The HWE is a principle stating that the genetic variation in a population will remain constant from one generation to the next in the absence of disturbing factors. The HWE can be disturbed by several factors including mutations, natural selection, nonrandom mating, and genetic drift. A significant result $(\mathrm{p}<0.05)$ means that controls are not in HWE [13]. SNPAnalyzerPro (ISTECH, Goyang, Korea), HelixTree (Golden Helix, Bozeman, United States), and SNPStats (http://bioinfo. iconcologia.net/index.php?module=Snpstats) were used to analyze genetic data. Multiple logistic regression models (codominant 1 , codominant 2, dominant, recessive, overdominant, and log-additive) were performed to determine the odds ratios (ORs), 95\% confidence intervals (CIs) and p-values, (age and gender were controlled as co-variables). For the statistical power, the required case size in each SNP was calculated using the genetic power calculator (http://pngu.mgh.harvard.edu/ purcell/gpc/ cc2.html). The statistical significance level was considered as a p-value below 0.05 .

\section{Genotyping of each SNP}

For the analysis of the genetic association between NOS1 polymorphisms and susceptibility to IS, multiple logistic regression analysis, adjusted for age and gender, was performed using the following: codominant 1 (major allele homozygotes vs. heterozygotes), codominant 2 (major allele homozygotes vs. minor allele homozygotes), dominant (major allele homozygotes vs. heterozygotes/ minor allele homozygotes), recessive (major allele homozygotes/heterozygotes vs. minor allele homozygotes), overdominant (major allele homozygotes/minor allele homozygotes vs. heterozygotes) and log-additive (major allele homozygotes vs. heterozygotes vs. minor allele homozygotes).

In the codominant model, every genotype gives a different and non additive risk. Therefore, we compared the major allele homozygotes that is the most frequent allele, to heterozygotes in codominant 1 and minor allele homozygotes in codominant 2 . In the dominant model a single copy of an allele is enough to modify the risk and heterozygous and homozygous genotypes have the same risk. In the recessive model two copies of the allele are necessary to change the risk. In the overdominant model heterozygotes are compared to both allele homozygotes. In the log-additive model each copy of the allele modifies the risk in an additive form.

\section{RESULTS}

\section{Clinical characteristics}

The clinical characteristics of patients with IS and control subjects are shown in Table 1. The age of IS and control subjects (mean \pm standard deviation) were $65.8 \pm 12.2$ and $63.1 \pm 9.4$ years, respectively. Stroke patients were divided according to clinical phenotypes which are NI- 
HSS (scores of 13 neurological symptoms; $<6$ or $\geq 6$ ), MBI (scores of 10 activities of general life; $<60$ or $\geq 60$ ), hypertension (present or absent) and diabetes mellitus (present or absent). The number of IS patients with NIHSS scores $<6$ and $\geq 6$ were 56 and 56 , respectively. The number of IS patients with MBI scores $<60$ and $\geq 60$ were 70 and 25, respectively. The number of IS patients with hyperten- sion present and absent were 80 and 35 , respectively. The number of IS patients with diabetes mellitus present and absent were 45 and 71, respectively. No control subjects had hypertension or diabetes mellitus (Table 1).

Table 2. Genotype frequencies of SNPs of nitric oxide synthase 1 (NOS1) genes in ischemic stroke patients and control subjects

\begin{tabular}{|c|c|c|c|c|c|c|}
\hline SNP & Type & Control group & IS group & Model & OR (95\% CI) & p-value \\
\hline rs2293054 & $\mathrm{C} / \mathrm{C}$ & $186(64.1)$ & $74(61.7)$ & Codominant1 & $1.10(0.69-1.75)$ & 0.7 \\
\hline Ile734Ile & $\mathrm{C} / \mathrm{T}$ & $90(31.0)$ & $39(32.5)$ & Codominant2 & $1.37(0.52-3.56)$ & 0.52 \\
\hline \multirow[t]{6}{*}{ cds-synon } & $\mathrm{T} / \mathrm{T}$ & $14(4.8)$ & $7(5.8)$ & Dominant & $1.13(0.73-1.76)$ & 0.59 \\
\hline & & & & Recessive & $1.33(0.52-3.41)$ & 0.56 \\
\hline & & & & Overdominant & $1.07(0.68-1.70)$ & 0.77 \\
\hline & & & & Log-additive & $1.13(0.79-1.62)$ & 0.51 \\
\hline & $\mathrm{C}$ & $462(79.7)$ & $187(77.9)$ & & 1 & \\
\hline & $\mathrm{T}$ & $118(20.3)$ & $53(22.1)$ & & $1.11(0.77-1.60)$ & 0.58 \\
\hline rs1047735 & $\mathrm{C} / \mathrm{C}$ & $74(25.5)$ & $33(27.5)$ & Codominant & $0.84(0.51-1.41)$ & 0.52 \\
\hline His902His & $\mathrm{C} / \mathrm{T}$ & $159(54.8)$ & $59(49.2)$ & Codominant2 & $1.15(0.62-2.14)$ & 0.65 \\
\hline \multirow[t]{6}{*}{ cds-synon } & $\mathrm{T} / \mathrm{T}$ & $57(19.7)$ & $28(23.3)$ & Dominant & $0.92(0.57-1.50)$ & 0.75 \\
\hline & & & & Recessive & $1.29(0.77-2.17)$ & 0.34 \\
\hline & & & & Overdominant & $0.79(0.51-1.22)$ & 0.29 \\
\hline & & & & Log-additive & $1.06(0.77-1.45)$ & 0.72 \\
\hline & $\mathrm{C}$ & 307 (52.9) & $125(52.1)$ & & 1 & \\
\hline & $\mathrm{T}$ & $273(47.1)$ & $115(47.9)$ & & $1.04(0.77-1.40)$ & 0.83 \\
\hline rs2293044 & $\mathrm{C} / \mathrm{C}$ & 258 (89) & $110(91.7)$ & Codominantl & $0.70(0.33-1.49)$ & 0.35 \\
\hline Val1353Val & $\mathrm{C} / \mathrm{A}$ & $31(10.7)$ & $10(8.3)$ & Dominant & $0.68(0.32-1.45)$ & 0.31 \\
\hline \multirow[t]{5}{*}{ cds-synon } & $\mathrm{A} / \mathrm{A}$ & $1(0.3)$ & $0(0)$ & Recessive & $0.00(0.00-\mathrm{NA})$ & 0.46 \\
\hline & & & & Overdominant & $0.70(0.33-1.50)$ & 0.35 \\
\hline & & & & Log-additive & $0.67(0.32-1.41)$ & 0.28 \\
\hline & $\mathrm{C}$ & 547 (94.3) & $230(95.8)$ & & 1 & \\
\hline & A & $33(5.7)$ & $10(4.2)$ & & $0.72(0.35-1.49)$ & 0.38 \\
\hline rs2682826 & $\mathrm{C} / \mathrm{C}$ & $146(50.3)$ & $55(45.8)$ & Codominantl & $1.18(0.75-1.86)$ & 0.46 \\
\hline \multirow[t]{7}{*}{ 3'UTR } & $\mathrm{C} / \mathrm{T}$ & $120(41.4)$ & $53(44.2)$ & Codominant2 & $1.35(0.63-2.90)$ & 0.45 \\
\hline & $\mathrm{T} / \mathrm{T}$ & $24(8.3)$ & $12(10)$ & Dominant & $1.21(0.79-1.87)$ & 0.38 \\
\hline & & & & Recessive & $1.24(0.60-2.59)$ & 0.57 \\
\hline & & & & Overdominant & $1.13(0.73-1.74)$ & 0.58 \\
\hline & & & & Log-additive & $1.17(0.84-1.63)$ & 0.35 \\
\hline & $\mathrm{C}$ & $412(71.0)$ & $163(67.9)$ & & 1 & \\
\hline & $\mathrm{T}$ & $168(29.0)$ & $77(32.1)$ & & $1.16(0.84-1.60)$ & 0.38 \\
\hline
\end{tabular}

Values are presented as number (\%).

SNP, single nucleotide polymorphism; IS, ischemic stroke; OR, odds ratio; CI, confidence interval; cds-synon, codon synonymous; UTR, untranslated region; NA, not applicable.

The p-values were calculated using logistic regression analyses adjusting for sex and age. 


\section{Analysis of IS susceptibility}

The genotype and allele distributions of the four selected SNPs are presented in Tables 2-4. The observed genotype distributions of the SNPs were in HWE ( $>0.05$ ). The genotype and allele distributions of the 4 SNPs among the IS group and control subjects are presented in Table 2. All 4 SNPs tested showed no statistically significant association between the IS and control subjects (Table 2).

\section{Analysis of clinical phenotypes}

All stroke patients were classified into clinical phenotypes according to the NIHSS score $(<6$ or $\geq 6)$ and the MBI score ( $<60$ or $\geq 60$ ). At first, we assessed the relationship between NOS1 SNPs and NIHSS scores of $<6$ or $\geq 6$. In the analysis of NIHSS, we observed a difference between NIHSS $<6$ group and NIHSS $\geq 6$ group (Table 3 ). The genotype frequencies of the CC, CT, and TT for rs2293054 were $0.48,0.45$, and 0.07 in the NIHSS $<6$ group, while

Table 3. Multiple logistic regression analysis of nitric oxide synthase 1 (NOS1) gene polymorphisms in ischemic stroke patients using NIHSS scores of $<6$ and $\geq 6$

\begin{tabular}{|c|c|c|c|c|c|c|}
\hline SNP & Type & NIHSS $<6$ & NIHSS $\geq 6$ & Model & OR (95\% CI) & p-value \\
\hline rs2293054 & $\mathrm{C} / \mathrm{C}$ & $27(48.2)$ & $41(73.2)$ & Codominantl & $0.38(0.17-0.85)$ & $0.019^{*}$ \\
\hline Ile734Ile & $\mathrm{C} / \mathrm{T}$ & $25(44.6)$ & $14(25)$ & Codominant2 & $0.15(0.02-1.46)$ & 0.1 \\
\hline \multirow[t]{6}{*}{ cds-synon } & $\mathrm{T} / \mathrm{T}$ & $4(7.1)$ & $1(1.8)$ & Dominant & $0.34(0.16-0.76)$ & $0.007^{*}$ \\
\hline & & & & Recessive & $0.21(0.02-2.02)$ & 0.13 \\
\hline & & & & Overdominant & $0.42(0.19-0.94)$ & $0.033^{*}$ \\
\hline & & & & Log-additive & $0.38(0.19-0.77)$ & $0.0048^{*}$ \\
\hline & $\mathrm{C}$ & $114(81.4)$ & $35(70)$ & & 1 & \\
\hline & $\mathrm{T}$ & $26(18.6)$ & $15(30)$ & & $0.40(0.21-0.78)$ & $0.007^{*}$ \\
\hline rs1047735 & $\mathrm{C} / \mathrm{C}$ & $16(28.6)$ & $15(26.8)$ & Codominantl & $1.07(0.43-2.63)$ & 0.89 \\
\hline His902His & $\mathrm{C} / \mathrm{T}$ & $30(53.6)$ & $28(50)$ & Codominant2 & $1.44(0.48-4.32)$ & 0.51 \\
\hline \multirow[t]{6}{*}{ cds-synon } & $\mathrm{T} / \mathrm{T}$ & $10(17.9)$ & $13(23.2)$ & Dominant & $1.17(0.50-2.73)$ & 0.72 \\
\hline & & & & Recessive & $1.38(0.54-3.54)$ & 0.5 \\
\hline & & & & Overdominant & $0.91(0.42-1.97)$ & 0.82 \\
\hline & & & & Log-additive & $1.19(0.69-2.05)$ & 0.53 \\
\hline & $\mathrm{C}$ & $77(55.0)$ & $25(50)$ & & 1 & \\
\hline & $\mathrm{T}$ & $63(45.0)$ & $25(50)$ & & $1.15(0.68-1.95)$ & 0.6 \\
\hline rs2293044 & $\mathrm{C} / \mathrm{C}$ & $50(89.3)$ & $52(92.9)$ & Codominantl & $0.59(0.15-2.27)$ & 0.44 \\
\hline Val1353Val & $\mathrm{C} / \mathrm{A}$ & $6(10.7)$ & $4(7.1)$ & & & \\
\hline \multicolumn{7}{|l|}{ cds-synon } \\
\hline & $\mathrm{C}$ & 134 (95.7) & 49 (98) & & 1 & \\
\hline rs2682826 & $\mathrm{C} / \mathrm{C}$ & $25(44.6)$ & $27(48.2)$ & Codominantl & $0.67(0.31-1.47)$ & 0.32 \\
\hline \multirow[t]{7}{*}{ 3'UTR } & $\mathrm{C} / \mathrm{T}$ & $29(51.8)$ & $21(37.5)$ & Codominant2 & $3.92(0.75-20.44)$ & 0.11 \\
\hline & $\mathrm{T} / \mathrm{T}$ & $2(3.6)$ & $8(14.3)$ & Dominant & $0.87(0.41-1.84)$ & 0.72 \\
\hline & & & & Recessive & $4.76(0.95-23.77)$ & $0.034^{*}$ \\
\hline & & & & Overdominant & $0.55(0.26-1.18)$ & 0.12 \\
\hline & & & & Log-additive & $1.20(0.67-2.15)$ & 0.53 \\
\hline & $\mathrm{C}$ & 97 (69.3) & $33(66)$ & & 1 & \\
\hline & $\mathrm{T}$ & $43(30.7)$ & $17(34)$ & & $1.18(0.67-2.08)$ & 0.56 \\
\hline
\end{tabular}

Values are presented as number (\%).

SNP, single nucleotide polymorphism; NIHSS, National Institute of Health Stroke Scale; OR, odds ratio; CI, confidence interval; cds-synon, codon synonymous; UTR, untranslated region.

The p-values were calculated using logistic regression analyses adjusting for sex and age.

${ }^{*} \mathrm{p}<0.05$ statistically significant. 
Table 4. Multiple logistic regression analysis of nitric oxide synthase 1 (NOS1) gene polymorphisms in ischemic stroke patients with MBI scores of $<60$ and $\geq 60$

\begin{tabular}{|c|c|c|c|c|c|c|}
\hline SNP & Type & MBI $<60$ & $\mathrm{MBI} \geq \mathbf{6 0}$ & Model & OR $(95 \% \mathrm{CI})$ & p-value \\
\hline rs2293054 & $\mathrm{C} / \mathrm{C}$ & $47(67.1)$ & $11(44)$ & Codominant1 & $2.98(1.06-8.32)$ & $0.038^{*}$ \\
\hline Ile734Ile & $\mathrm{C} / \mathrm{T}$ & $20(28.6)$ & $13(52)$ & Codominant2 & $3.22(0.23-45.23)$ & 0.39 \\
\hline \multirow{6}{*}{ cds-synon } & $\mathrm{T} / \mathrm{T}$ & $3(4.3)$ & $1(4)$ & Dominant & $2.99(1.09-8.21)$ & $0.031^{*}$ \\
\hline & & & & Recessive & $2.02(0.15-26.56)$ & 0.61 \\
\hline & & & & Overdominant & $2.77(1.02-7.57)$ & $0.045^{*}$ \\
\hline & & & & Log-additive & $2.47(1.04-5.88)$ & $0.04^{*}$ \\
\hline & $\mathrm{C}$ & $114(95.7)$ & $35(95.7)$ & & 1 & \\
\hline & $\mathrm{T}$ & $26(4.3)$ & $15(4.3)$ & & $1.88(0.90-3.94)$ & 0.95 \\
\hline rs1047735 & $\mathrm{C} / \mathrm{C}$ & $22(31.4)$ & $4(16)$ & Codominantl & $2.17(0.61-7.74)$ & 0.23 \\
\hline His902His & $\mathrm{C} / \mathrm{T}$ & $33(47.1)$ & $17(68)$ & Codominant2 & $1.73(0.34-8.78)$ & 0.51 \\
\hline \multirow[t]{6}{*}{ cds-synon } & $\mathrm{T} / \mathrm{T}$ & $15(21.4)$ & $4(16)$ & Dominant & $2.06(0.60-7.10)$ & 0.23 \\
\hline & & & & Recessive & $1.00(0.27-3.73)$ & 1 \\
\hline & & & & Overdominant & $1.71(0.62-4.76)$ & 0.3 \\
\hline & & & & Log-additive & $1.35(0.63-2.90)$ & 0.44 \\
\hline & $\mathrm{C}$ & 77 (95.7) & $25(95.7)$ & & 1 & \\
\hline & $\mathrm{T}$ & $63(4.3)$ & $25(4.3)$ & & $1.22(0.64-2.33)$ & 0.54 \\
\hline rs2293044 & $\mathrm{C} / \mathrm{C}$ & $64(91.4)$ & $24(96)$ & Codominantl & $0.61(0.06-5.80)$ & 0.65 \\
\hline Val1353Val & $\mathrm{C} / \mathrm{A}$ & $6(8.6)$ & $1(4)$ & & & \\
\hline \multicolumn{7}{|l|}{ cds-synon } \\
\hline & $\mathrm{C}$ & $134(95.7)$ & 49 (95.7) & & 1 & \\
\hline & A & $6(4.3)$ & $1(4.3)$ & & $0.46(0.54-3.89)$ & 0.47 \\
\hline rs2682826 & $\mathrm{C} / \mathrm{C}$ & $34(48.6)$ & $10(40)$ & Codominantl & $1.50(0.54-4.18)$ & 0.44 \\
\hline \multirow[t]{7}{*}{ 3'UTR } & $\mathrm{C} / \mathrm{T}$ & $29(41.4)$ & $13(52)$ & Codominant2 & $0.85(0.14-5.18)$ & 0.86 \\
\hline & $\mathrm{T} / \mathrm{T}$ & $7(10.0)$ & $2(8)$ & Dominant & $1.36(0.51-3.64)$ & 0.54 \\
\hline & & & & Recessive & $0.69(0.12-3.90)$ & 0.67 \\
\hline & & & & Overdominant & $1.55(0.58-4.11)$ & 0.38 \\
\hline & & & & Log-additive & $1.11(0.53-2.33)$ & 0.78 \\
\hline & $\mathrm{C}$ & 97 (95.7) & 33 (95.7) & & 1 & \\
\hline & $\mathrm{T}$ & $43(4.3)$ & $17(4.3)$ & & $1.16(0.59-2.31)$ & 0.67 \\
\hline
\end{tabular}

Values are presented as number (\%).

SNP, single nucleotide polymorphism; MBI, Modified Barthel Index; OR, odds ratio; CI, confidence interval; cds-synon, codon synonymous; UTR, untranslated region.

The p-values were calculated using logistic regression analyses adjusting for sex and age.

${ }^{*} \mathrm{p}<0.05$ statistically significant.

they were $0.73,0.25$, and 0.02 in the NIHSS $\geq 6$ group. The CT genotype frequency of rs2293054 differed between the NIHSS $<6$ group and NIHSS $\geq 6$ group ( $44.6 \%$ vs. $25 \%$ ). The rs2293054 was associated with IS in the codominant model (OR, 0.38; 95\% CI, 0.17-0.85; $\mathrm{p}=0.019$ ), dominant model (OR, 0.34; 95\% CI, 0.16-0.76; $\mathrm{p}=0.007$ ), overdominant (OR, 0.42; 95\% CI, 0.19-0.94; $\mathrm{p}=0.033$ ), and logadditive model (OR, 0.38; 95\% CI, 0.19-0.77; $\mathrm{p}=0.0048$ ).
In the allele frequency analysis, we also found that the $\mathrm{T}$ alleles of rs2293054 were associated with lower NIHSS scores (OR, 0.40; 95\% CI, 0.21-0.78; $\mathrm{p}=0.007$ ) (Table 3). Also, the genotype frequencies of the CC, CT, and TT for rs2682826 were $0.45,0.52$, and 0.04 in the NIHSS $<6$ group, while they were $0.48,0.38$, and 0.14 in the NIHSS $\geq 6$ group. The CT genotype frequency of rs 2682826 was not different between the NIHSS $<6$ group and NIHSS $\geq 6$ 
group (51.8\% vs. $37.5 \%)$. The rs2682826 was not associated with NIHSS scores in the codominant model (OR, 0.67; 95\% CI, 0.31-1.47; $\mathrm{p}=0.32$ ), dominant model (OR, 0.87; 95\% CI, 0.41-1.84; $\mathrm{p}=0.72$ ), overdominant model (OR, 0.55; 95\% CI, 0.26-1.18; $\mathrm{p}=0.12$ ), and log-additive model (OR, 1.20; 95\% CI, 0.67-2.15; p=0.53). But, rs2682826 revealed a significant association in recessive model (OR, 4.76; 95\% CI, 0.95-23.77; $\mathrm{p}=0.034$ ). Secondly, in multiple logistic regression analysis of NOS1 polymorphisms in IS patients with MBI scores of $<60$ or $\geq 60$, rs2293054 had significant association within the codominant model (OR, 2.98; 95\% CI, 1.06-8.32; $\mathrm{p}=0.038$ ), dominant model (OR, 2.99; 95\% CI, 1.09-8.21; $\mathrm{p}=0.031$ ), overdominant model (OR, 2.77; 95\% CI, 1.02-7.57; $\mathrm{p}=0.045$ ), and log-additive model (OR, 2.47; 95\% CI, 1.04-5.88; $\mathrm{p}=0.04$ ), respectively. The rs1047735 and rs2293044 were not statistically associated with NIHSS scores $(<6$ or $\geq 6)$, and MBI scores $(<60$ or $\geq 60$ ).

\section{DISCUSSION}

Several polymorphisms of the neuronal NOS1 gene have been reported to be associated with impulsivity, aggression, and suicide attempts [14], high-grade renal cell carcinoma [15], end stage renal disease susceptibility [16], asthma and cystic fibrosis [17-20], infantile hypertrophic pyloric stenosis [21], and systolic heart failure [9]. In the viewpoint of polymorphisms related to IS, NOS3 appears beneficial via vasodilatation and inhibition of leukocyte adhesion and platelet aggregation. By contrast, NOS1 and NOS2 were demonstrated to be deleterious in cases of cerebral ischemia [6]. Recent studies suggested that NOS1 may have a crucial vasculoprotective role in atherosclerosis and is involved in blood pressure control [22]. NOS1 influences stroke susceptibility through very different mechanisms from NOS3. A significant association of the NOS1 gene, with stroke susceptibility, have been reported [10]. Manso et al. [10] showed that associated SNPs and haplotypes of NOS1 were located in the critical gene regions, namely the NOS domain and the PDZ domain, required to anchor NOS1 to the cellular membrane. Four SNPs (rs2293050, rs2139733, rs7308402 and rs1483757) were found to have a significant relationship with the development of IS. However, no relationship was found with the clinical severity of IS. As mentioned above, the aim of our study was to investigate different
SNPs from previous studies, and evaluate not only the genetic association between NOS1 polymorphisms and the susceptibility of IS, but also the clinical phenotypes of IS patients in a Korean population.

We classified stroke patients into clinical phenotypes according to the NIHSS score $(<6$ or $\geq 6)$ and the MBI score ( $<60$ or $\geq 60$ ). In a previous study, patients with MBI score higher than 60 required shorter home stays. In this study, an MBI score of 60 appeared to be a reference point to whether patients are dependent or independent or requires only partial assistance [23]. In terms of NIHSS score, score below 6 predicted a good outcome in a study consisting of 1,281 stroke patients [24].

The NOS1 (also known as nNOS and IHPS1), which is located on chromosome 12q24.2-q24.31, produce NO in a reaction that converts arginine and oxygen into citrulline and NO [25]. NO is a reactive free radical, which acts as a biologic mediator in several processes, including neurotransmission, antimicrobial, and antitumoral activities. In the brain and peripheral nervous system, NO displays many properties of a neurotransmitter and has been implicated in neurotoxicity associated with stroke and neurodegenerative diseases, neural regulation of smooth muscle including peristalsis, and penile erection. NOS1 protein (P29475, UniProtKB/Swiss-Prot) consists of 1,434 amino acids, and has a molecular mass of 160,970 Da. Mammalian NOS consist of an oxygenase domain (heme and $\mathrm{H} 4 \mathrm{~B}$ binding) and a reductase domain related by sequence, structure and function to NADPH-dependent microsomal cytochrome $\mathrm{P} 450$ reductase. The NOS reductase domain can be further divided into FMN and FAD binding domains, linked together by a single polypeptide chain. The FMN domain is connected to the oxygenase domain, via a segment of polypeptide about 30 amino acids in length, which forms a binding site for calmodulin (amino acids from 730 to 750 ) [8]. Our results suggest that the coding SNP (rs2293054, exon 16, 734th amino acid of NOS1 protein) (http://www.uniprot.org/uniprot/ P29475) in the NOS1 gene contributes to the susceptibility to the clinical phenotype such as NIHSS and MBI in IS patients (Tables 3, 4). In terms of location on NOS1 gene, the rs2293054 SNPs may be related to the function of the calmodulin domain of NOS1.

Hancock et al. [26] found that significant associations with Parkinson's disease were detected for the NOS1 SNPs especially rs2682826 (3'UTR, untranslated region). 
In our study, we found an association between rs2682826 and NIHSS scores in the recessive model (OR, 4.76; 95\% CI, 0.95-23.77; $\mathrm{p}=0.034$ ). The genotype frequencies and T-allele of the rs2293054 SNP for the NOS1 in Parkinson's disease or stroke patients was not associated with disease susceptibility or was not reported $[10,26]$. In another study, the relationship between rs2293054 SNP and cognitive aging was tested but no relationship could be found [27]. To our knowledge these two studies are the only ones to investigate the relationship of rs2293054 SNP and clinical diseases [26,27]. As mentioned above, none of these studies found significant results of rs2293054 SNP. However, we found the association between rs2293054 and NIHSS or MBI scores in the codominant model, dominant model, overdominant model and logadditive model. Therefore, the T-allele of the rs2293054 may contribute to the pathogenesis of clinical phenotypes in patients with IS.

In previous studies conducted in the Chinese population, rs1047735 SNP showed no relationship with glioma and infertility $[28,29]$. It also showed no relationship with Parkinson's disease [26]. Furthermore, there are no studies investigating the clinical role of rs2293044 SNP. Like these previous studies, we also found no clinical importance for these two SNPs. Further study is required to determine whether rs1047735 SNP and rs2293044 SNP play a clinical role.

In our study, 121 IS patients were enrolled. Compared to previous studies evaluating SNPs, the sample size is small and therefore our results need to be replicated in other populations. Another limitation of this study is that although NIHSS and MBI are one of the most widely used scales to measure stroke outcome, stroke outcome is influenced by multiple factors including rehabilitation treatment and pharmacotherapy, which were not assessed in our study.

In conclusion, we observed the association between clinical phenotype and coding polymorphisms (rs2293054, Ile734Ile) in the NOS1 gene in the Korean population. These results suggest that NOS1 gene may affect susceptibility to clinical phenotypes of IS.

\section{CONFLICT OF INTEREST}

No potential conflict of interest relevant to this article was reported.

\section{ACKNOWLEDGMENTS}

This research was supported by the Kyung Hee University Research Fund in 2006 (No. KHU-20060452).

\section{REFERENCES}

1. Donnan GA, Fisher M, Macleod M, Davis SM. Stroke. Lancet 2008;371:1612-23.

2. Deb P, Sharma S, Hassan KM. Pathophysiologic mechanisms of acute ischemic stroke: An overview with emphasis on therapeutic significance beyond thrombolysis. Pathophysiology 2010;17:197-218.

3. Durukan A, Tatlisumak T. Acute ischemic stroke: overview of major experimental rodent models, pathophysiology, and therapy of focal cerebral ischemia. Pharmacol Biochem Behav 2007;87:179-97.

4. Dominiczak AF, McBride MW. Genetics of common polygenic stroke. Nat Genet 2003;35:116-7.

5. Matarin M, Brown WM, Dena H, Britton A, De Vrieze FW, Brott TG, et al. Candidate gene polymorphisms for ischemic stroke. Stroke 2009;40:3436-42.

6. Plotkine M, Margaill I. NO synthases: new pharmacological targets in cerebrovascular accident?. Therapie 2002;57:548-53.

7. Forstermann U, Closs EI, Pollock JS, Nakane M, Schwarz P, Gath I, et al. Nitric oxide synthase isozymes: characterization, purification, molecular cloning, and functions. Hypertension 1994;23(6 Pt 2):1121-31.

8. Daff S. NO synthase: structures and mechanisms. Nitric Oxide 2010;23:1-11.

9. Martinelli NC, Santos KG, Biolo A, La Porta VL, Cohen CR, Silvello D, et al. Polymorphisms of endothelial nitric oxide synthase gene in systolic heart failure: an haplotype analysis. Nitric Oxide 2012;26:141-7.

10. Manso H, Krug T, Sobral J, Albergaria I, Gaspar G, Ferro JM, et al. Variants within the nitric oxide synthase 1 gene are associated with stroke susceptibility. Atherosclerosis 2012;220:443-8.

11. Chon J, Hong JH, Kim J, Han YJ, Lee BW, Kim SC, et al. Association between $\mathrm{BH} 3$ interacting domain death agonist (BID) gene polymorphism and ossification of the posterior longitudinal ligament in Korean population. Mol Biol Rep 2014;41:895-9.

12. Park HJ, Yun DH, Kim SK, Chung JH, Lee JS, Park HK, et al. Association of CXCL1 promoter polymorphism 
with ischaemic stroke in Korean population. Int J Immunogenet 2013;40:306-10.

13. Kang SH, Shin D. The size of the chi-square test for the Hardy-Weinberg law. Hum Hered 2004;58:10-7.

14. Cui H, Supriyanto I, Asano M, Ueno Y, Nagasaki Y, Nishiguchi N, et al. A common polymorphism in the 3'-UTR of the NOS1 gene was associated with completed suicides in Japanese male population. Prog Neuropsychopharmacol Biol Psychiatry 2010;34:992-6.

15. Renaudin K, Denis MG, Karam G, Vallette G, Buzelin F, Laboisse CL, et al. Loss of NOS1 expression in highgrade renal cell carcinoma associated with a shift of NO signalling. Br J Cancer 2004;90:2364-9.

16. Freedman BI, Yu H, Anderson PJ, Roh BH, Rich SS, Bowden DW. Genetic analysis of nitric oxide and endothelin in end-stage renal disease. Nephrol Dial Transplant 2000;15:1794-800.

17. Gao PS, Kawada H, Kasamatsu T, Mao XQ, Roberts $\mathrm{MH}$, Miyamoto Y, et al. Variants of NOS1, NOS2, and NOS3 genes in asthmatics. Biochem Biophys Res Commun 2000;267:761-3.

18. Ali M, Khoo SK, Turner S, Stick S, Le Souef P, Franklin P. NOS1 polymorphism is associated with atopy but not exhaled nitric oxide levels in healthy children. Pediatr Allergy Immunol 2003;14:261-5.

19. Leung TF, Liu EK, Tang NL, Ko FW, Li CY, Lam CW, et al. Nitric oxide synthase polymorphisms and asthma phenotypes in Chinese children. Clin Exp Allergy 2005;35:1288-94.

20. Shao C, Suzuki Y, Kamada F, Kanno K, Tamari M, Hasegawa $\mathrm{K}$, et al. Linkage and association of childhood asthma with the chromosome 12 genes. J Hum Genet 2004;49:115-22.

21. Serra A, Schuchardt K, Genuneit J, Leriche C, Fitze G. Genomic variants in the coding region of neuronal nitric oxide synthase (NOS1) in infantile hypertrophic pyloric stenosis. J Pediatr Surg 2011;46:1903-8.

22. Toda N, Ayajiki K, Okamura T. Control of systemic and pulmonary blood pressure by nitric oxide formed through neuronal nitric oxide synthase. J Hypertens 2009;27:1929-40.

23. Granger CV, Dewis LS, Peters NC, Sherwood CC, Barrett JE. Stroke rehabilitation: analysis of repeated Barthel index measures. Arch Phys Med Rehabil 1979;60:14-7.

24. Adams HP Jr, Davis PH, Leira EC, Chang KC, Bendixen BH, Clarke WR, et al. Baseline NIH Stroke Scale score strongly predicts outcome after stroke: A report of the Trial of Org 10172 in Acute Stroke Treatment (TOAST). Neurology 1999;53:126-31.

25. Kanwar JR, Kanwar RK, Burrow H, Baratchi S. Recent advances on the roles of NO in cancer and chronic inflammatory disorders. Curr Med Chem 2009;16:237394.

26. Hancock DB, Martin ER, Vance JM, Scott WK. Nitric oxide synthase genes and their interactions with environmental factors in Parkinson's disease. Neurogenetics 2008;9:249-62.

27. Harris SE, Fox H, Wright AF, Hayward C, Starr JM, Whalley LJ, et al. A genetic association analysis of cognitive ability and cognitive ageing using 325 markers for 109 genes associated with oxidative stress or cognition. BMC Genet 2007;8:43.

28. Yan L, Guo W, Wu S, Liu J, Zhang S, Shi L, et al. Genetic variants in nitric oxide synthase genes and the risk of male infertility in a Chinese population: a casecontrol study. PLoS One 2014;9:e115190.

29. Zhao P, Zhao L, Zou P, Lu A, Liu N, Yan W, et al. Genetic oxidative stress variants and glioma risk in a Chinese population: a hospital-based case-control study. BMC Cancer 2012;12:617. 